\title{
Juegos coreográficos que dan sentido al preescolar
}

Astrid Ximena Santos *

Artículo de investigación

Fecha de Recepción: 2 diciembre 2017.

Fecha de Aprobación: 29 abril 2018.

\section{Resumen}

El presente artículo da cuenta de los avances de una investigación que se está desarrollando en el nivel preescolar, en una institución educativa del municipio de Duitama (Boyacá). Partiendo de la revisión de estudios que revelan la importancia de la devolución de sentido al nivel de educación preescolar, ante la visión adultocéntrica, utilitarista y academicista contemporánea generada por el progresivo fortalecimiento de la privatización de la educación, donde la primera infancia se concibe en gran medida como sinónimo de lucrativo negocio conllevando a desdibujar la integralidad en las prácticas educativas actuales. Posteriormente se describen los sustentos teóricos que fundamentan el estudio. Se refiere el enfoque metodológico de carácter cualitativo y la investigación acción educativa, acudiendo a las observaciones y los diarios de campo, para llevar a cabo procesos de autorreflexión y reflexión pedagógica, sobre el quehacer docente, con el propósito de conocer el significado que la maestra le da a la educación preescolar, teniendo en cuenta las características del ambiente, las formas de las relaciones, los ambientes de aprendizaje, las formas de trabajo, las estrategias que utiliza y las actividades que presentan más relevancia.

Palabras clave: Educación preescolar, juego coreográfico, integralidad, resignificación y sentido.
* Instituto Técnico Nueva Familia - Duitama astridximena.santos@ gmail.com 


\section{Introducción}

Según la Ley General de Educación (Ley 115, 1994, Art. 15), la educación preescolar "corresponde a la ofrecida al niño menor de seis (6) años, para su desarrollo integral en los aspectos biológico, cognoscitivo, sicomotriz, socio-afectivo y espiritual, a través de experiencias desocialización pedagógicas y recreativas". Este nivel está compuesto por siete grados, los cuales en su mayoría son atendidos principalmente por el sector privado y solamente "uno", el último, por las instituciones del sector público, por estar comprendido dentro de la educación formal como grado obligatorio.

Teniendo en cuenta la realidad mencionada, aunada a la permanente transformación suscitada en la actualidad donde se desarrolla, emerge una situación singular para la primera infancia, que se ha convertido en el codiciado insumo ante el fortalecimiento del sector privado que la acapara en su servicio educativo con fines principalmente económicosproductivos, como lo afirma Tadeu da Silva (1997) cuando habla del "asalto neoliberal al sentido común sobre la educación pública producido por el modernismo y el iluminismo, y el consecuente dislocamiento de la educación de la esfera del espacio público al espacio privado del consumo y la selección” (p.2).

Por esta razón, se hace necesario $\mathrm{y}$ trascendente generar espacios de autorreflexión profesional, en un momento de la historia donde la infancia es tan o más vulnerable porque es vista como un lucrativo negocio.

Dicha perspectiva desvía el sentido de la educación preescolar al punto de exigir resultados anteponiendo el saber y desconociendo la esencia e integralidad del ser desdibujando la práctica pedagógica actual, situación producida también, por la falta de empoderamiento de las docentes de este nivel, quienes han permitido el desplazamiento progresivo del juego en sus aulas reemplazándolo por una academización en aumento, para lograr niños/as que, sentados quietos, en resumen: lean, escriban, sumen y resten cada vez en edad más temprana, ante la aprobación de los padres quienes la confunden como sinónimo de calidad.

Lo anterior, lleva a desarrollar una investigación de carácter cualitativo orientada por la pregunta: ¿De qué manera resignificar el sentido de la educación preescolar en la práctica pedagógica de los niños de transición de una institución educativa del municipio de Duitama en el departamento de Boyacá? Partiendo de una definición del problema a investigar, apoyado en una revisión bibliográfica desde diversos autores, comenzando con la concepción de infancia propuesta por Jaramillo (2007) apoyada en los planteamientos de Rousseau, Piaget, Vigotsky y Freire.

Posteriormente se aborda el sentido de la educación preescolar alrededor del juego como actividad rectora estrechamente vinculada al principio de lúdica, respaldado en los documentos 
oficiales como las normas relativas a la prestación del servicio educativo del nivel preescolar el (Decreto 2247, 1997), la Ley 115 (1994), los Lineamientos Curriculares para Preescolar (1998) y la serie de orientaciones pedagógicas para la educación inicial en el marco de la atención integral: Sentido de la educación inicial (Documento No.20, 2014). De igual manera, autores como Groos (1902), Vigotsky (1924), Piaget (1956), Bruner (1995), Huizinga (2000) y de la Organización de las Naciones Unidas (ONU, 1959) con la declaración de los derechos del niño. Finalmente se destaca de manera específica el juego coreográfico con autores como López, \& Valbuena (2015), Robinson (1992), Laban (2006), Peña \& Castro (2012) y Tonucci (2015).

Sinlugaradudas, la revisiónbibliográfica contribuye a la sensibilización del sentido que la educación preescolar debe tener en la infancia, visibilizada en formas de trabajo pertinentes a la edad y grado, donde los niños(as) pueden descubrir sus talentos a partir del juego coreográfico desarrollando sus habilidades rítmicas, expresivas, comunicativas, sociales y cognitivas a partir de la expresión corporal, verbal, gráfica y de la música. Convirtiéndose en un posible dispositivo de empoderamiento para dar sentido al quehacer pedagógico, permitiendo al maestro reflexionar acerca del mismo y replantearlo. Además, permeando la nociva, acomodada y rutinaria cotidianidad en la que están inmersas las prácticas educativas preescolares actuales, punto de partida para favorecer la integralidad de la infancia, desde la pertinencia de la práctica pedagógica que ella requiere y merece.

\section{Sustentos Teóricos}

A continuación, se relacionan algunas investigaciones realizadas sobre el sentido de la educación preescolar y los juegos coreográficos, las cuales han servido como referente, en varios aspectos de la presente investigación.

El trabajo investigativo realizado por la Pontificia Universidad Javeriana y la Universidad Autónoma de Puebla: "El juego temático de roles sociales: aportes al desarrollo en la edad preescolar" (González, Solovieva, \& Quintanar, 2014), ratifica la importancia del juego temático de roles sociales en la educación preescolar como posibilitador del desarrollo de las actividades: simbólica, reflexiva, comunicativa, voluntaria, imaginativa y desplegada. Reconociendo el juego como factor indispensable en la edad preescolar para el desempeño exitoso posterior y abordando específicamente el juego simbólico del cual forma parte también el coreográfico como en el presente documento.

En la Universidad de Chile, el artículo "Sociología de la infancia: los niños y las niñas como actores sociales" (Soto Pavez, 2012) aporta una reflexión sobre la concepción de infancia resaltando la actuación de los niños y niñas a través de la historia en una sociedad adulta o adultocéntrica que no siempre los reconoce. Visión abordada en el desarrollo investigativo actual.
Sin lugar a dudas, la revisión bibliográfica contribuye a la sensibilización del sentido que la educación preescolar debe tener en la infancia, visibilizada en formas de trabajo pertinentes a la edad y grado, donde los niños(as) pueden descubrir sus talentos a partir del juego coreográfico desarrollando sus habilidades rítmicas, expresivas, comunicativas, sociales y cognitivas a partir de la expresión corporal, verbal, gráfica y de la música. 
El trabajo titulado "Rondas, Rimas y juegos coreográficos como recursos lúdicos de mejoramiento convivencial" (Montero, Moreno, \& Veloza, 2015), hizo énfasis en los espacios innovadores de juego logrando romper con la cotidianidad, mejorando la convivencia y propendiendo por el aprendizaje significativo mediante el aprovechamiento de rondas, rimas y retahílas como expresión cultural. Aportando a la presente investigación lo referente al desarrollo de la convivencia a través de los juegos coreográficos en concordancia con el sentido de la educación Preescolar en lo que concierne al desarrollo de habilidades sociales.

Asimismo, la investigación titulada: "influencia del juego coreográfico en los procesos de atención y memoria de los niños de grado primero jornada tarde del Colegio Marsella" (Cruz, 2016), destaca la importancia de la práctica de movimientos rítmicos y juegos coreográficos para el favorecimiento de procesos básicos superiores como la atención y la memoria y por consiguiente el mejoramiento del aprendizaje. Siendo su principal aporte a la presente investigación la manera en que las habilidades que pueden desarrollarse en los niños/as a través del juego coreográfico.

Además, en el artículo: "el juego y sus posibilidades en la enseñanza de las ciencias naturales" (Melo \& Hernández, 2014) de la Universidad Autónoma de Colombia, se reconoce el juego como actividad aportante a la construcción del individuo y la sociedad, el cual, enmarcado de forma didáctica propicia el desarrollo cognitivo, afectivo y comunicativo como aspectos determinantes. Por tanto, contribuye de manera relevante al reconocimiento del juego como dinamizador $y$ potencializador del aprendizaje y su importancia en la cotidianidad escolar para la construcción de conocimiento científico.

De igual manera, la investigación "El sentido de la relación juego coreográfico - bailes populares en la recreación : una revisión bibliográfica” (Tovar, 2016) está relacionada con la experiencia del profesional como recreador $y$ propiciador de cultura desde las expresiones autóctonas, contribuyendo con una visión integradora para asumir la misión de recrear pedagógicamente con los lenguajes del arte, encontrando proyectos sociales que re- significan los sentidos de vida creativamente.

Por otra parte, el trabajo de maestría: "políticas públicas y orientaciones pedagógicas como fundamento para la construcción del currículo para la educación musical en preescolar" (Másmela \& Pacheco, 2014) propone los lineamientos curriculares para educación musical en preescolar, teniendo como base las políticas públicas, así como los elementos teóricos y metodológicos existentes; elementos que pueden involucrarse al presente proyecto con relación a la música en los juegos coreográficos.

Finalmente la investigación: "estrategias didácticas del juego coreográfico que resignifican la enseñanza de 
la danza en la básica primaria de instituciones educativas de Bogotá" (Hernández, 2015) de la Universidad de la Salle, reconoce y propone el juego coreográfico como dispositivo que resignifica el quehacer pedagógico, en este caso desde la danza que, al igual que en el presente trabajo encara las realidades palpables sumergidas en la enseñanza tradicional, rígida y rutinaria.

De esta manera, las investigaciones anteriores se convierten en insumos para el desarrollo de la presente con miras a ampliar específicamente el horizonte inexplorado de la educación preescolar respecto a su sentido particular.

\section{Teorías del conocimiento}

Partiendo de que ésta propuesta se desarrolla en el ámbito infantil, es pertinente revisar la concepción de primera infancia citada por Jaramillo (2007):

Se entiende por primera infancia el periodo de la vida, de crecimiento y desarrollo comprendido desde la gestación hasta los 7 años aproximadamente y que se caracteriza por la rapidez de los cambios que ocurren. Esta primera etapa es decisiva en el desarrollo, pues de ella va a depender toda la evolución posterior del niño en las dimensiones motora, lenguaje, cognitiva y socioafectiva, entre otras. (p. 110)

Entonces, lo dicho refiere un principio de integralidad cuando menciona las dimensiones $\mathrm{y}$, por consiguiente, esta primera etapa es decisiva en el desarrollo humano. En otro apartado la misma autora alude a que "La noción de infancia tiene un carácter histórico y cultural y es por ello que ha tenido diferentes apreciaciones en la historia; su concepción depende del contexto cultural de la época” (p.110), lo que significa que no ha permanecido estática sino ha sido cambiante a través de los años: desde un principio asistencialista en el inicio a uno que seguramente debe o debería ser más pertinente en la actualidad.

En relación con lo expuesto, la infancia es una etapa crucial que incide en el ser humano de manera definitiva. De ahí la importancia del rol del docente que en el preescolar recibe el privilegio, la delicada misión de formar en estos primeros años, aquí es donde intervienen las bases teóricas del mismo en educación, pedagogía y didáctica, tan necesarias para desarrollar de forma apropiada las habilidades inherentes a su quehacer pedagógico dando y manteniendo el sentido particular de la educación inicial.

Lo anterior lleva a realizar una revisión acerca de la pedagogía en la infancia, por ello es necesario hacer un recorrido por el tiempo, interiorizando los principales planteamientos de diversos autores desde Jean Jacques Rousseau con su mirada educativa como forma de dominio social, pasando por Jean Piaget con su psicología evolutiva, sobre los estadios de desarrollo del niño y Lev Vygotsky quien vincula además la influencia del entorno para este desarrollo; sin dejar de lado pensadores contemporáneos
Se entiende por primera infancia el periodo de la vida, de crecimiento y desarrollo comprendido desde la gestación hasta los 7 años aproximadamente y que se caracteriza por la rapidez de los cambios que ocurren. Esta primera etapa es decisiva en el desarrollo, pues de ella va a depender toda la evolución posterior del niño en las dimensiones motora, lenguaje, cognitiva y socioafectiva, entre otras. 
El Estado, la sociedad y la familia son responsables de la educación, que será obligatoria entre los cinco y los quince años de edad y que comprenderá como mínimo, un año de preescolar como Paulo Freire con su pedagogía emancipatoria, lo cual es relevante en la formación del docente porque le posibilita comprender la evolución de la educación y de la misma infancia, al igual que el papel fundamental que él juega como aportante y transformador de la realidad, una realidad que grita, ha gritado a lo largo de la historia y continúa gritando y demandando una seria mirada a la infancia, a la primera infancia tan desdibujada hoy por intereses ajenos a su esencia.

En lo que se refiere al sentido de la educación preescolar, en Colombia la educación preescolar "corresponde a la ofrecida al niño menor de seis (6) años, para su desarrollo integral en los aspectos biológico, cognoscitivo, sicomotriz, socio-afectivo y espiritual, a través de experiencias de socialización pedagógicas y recreativas". (Ley 115, 1994). Este nivel está compuesto por siete grados: de 0 a 2 años (salacuna, gateadores, caminadores y párvulos) y de 3 a 5 años (prejardín, jardín y transición); de los cuales "siete" son atendidos principalmente por el sector privado y solamente "uno", el último, por las instituciones del sector público, por estar comprendido dentro de la educación formal como grado obligatorio según el Artículo 67 (Constitución Politica de Colombia, 1991) “... El Estado, la sociedad y la familia son responsables de la educación, que será obligatoria entre los cinco y los quince años de edad y que comprenderá como mínimo, un año de preescolar...”.

De igual forma plantea en el Articulo 16 (Ley 115, 1994) los objetivos de la educación preescolar que en resumen son el conocimiento del propio cuerpo, el crecimiento armónico y equilibrado del niño, el desarrollo de la creatividad, la ubicación espacio-temporal y el ejercicio de la memoria; el desarrollo de la capacidad para adquirir formas de expresión, relación y comunicación y para establecer relaciones de reciprocidad, la participación en actividades lúdicas con otros niños y adultos; el estímulo a la curiosidad para observar y explorar el medio natural, familiar y social, el reconocimiento de su dimensión espiritual, la vinculación de la familia y la comunidad al proceso educativo y la formación de hábitos saludables.

En concordancia, se decretan el 11 de Septiembre de 1994 las normas relativas a la prestación del servicio del nivel de educación preescolar, mediante artículos que permiten realizar un trabajo de calidad con los niños y niñas planteado bajo tres principios pedagógicos: integralidad, participación y lúdica, éste último "reconoce el juego como dinamizador de la vida del educando" (Decreto 2247, 1997) los cuales promueven a través de los proyectos lúdicos pedagógicos un aprendizaje más armónico y acorde a las necesidades e intereses del niño y la niña. Lo que se plantea en este documento, es que de acuerdo al significado $y$ sentido del preescolar se maneje una integralidad de las dimensiones donde se vea al niño como un todo y no de manera segmentada, porque el niño en esta etapa es un ser en desarrollo, una unidad biopsicosocial con características, físicas, psicológicas y sociales propias y particulares. 
Respecto a lo anterior, se destaca que "la educación contribuye al desarrollo humano en todas sus dimensiones" (Decreto 2247, 1997) desde los pilares de aprender a ser, a conocer, a hacer y a vivir juntos. De esta manera, en el Preescolar se contemplan siete dimensiones que son: la corporal, la ética, la estética, la socioafectiva, la espiritual, la cognitiva y la comunicativa; donde se puede definir a la dimensión como la extensión comprendida por un aspecto de desarrollo, y, aunque son presentadas de manera separada con fines explicativos, se abordan de manera integrada, simultánea y complementaria teniendo en cuenta que el desarrollo es un proceso integral.

En el caso de las dimensiones, en la serie lineamientos curriculares preescolar (MEN, 1998) se encuentra la definición de cada una de ellas (Ver figura 1).

Figura 1. Lineamientos curriculares preescolar
Del mismo modo, las nuevas políticas públicas resaltan la importancia de potenciar las habilidades en los niños (as) a través del reconocimiento de las dimensiones en la educación inicial, en el Documento No. 20 Sentido de la Educación Inicial - Serie de orientaciones pedagógicas para la atención integral de la primera infancia (MEN, 2014) se precisa que

el ambiente educativo trasciende la mirada plana de su organización para convocar a maestras, maestros y agentes educativos a enriquecerlo, de manera que responda con claridad a las particularidades de las niñas y los niños y, al mismo tiempo, les proponga múltiples posibilidades para crear, transformar, significar, comprender y participar en su configuración. Así, por ejemplo, cuando se disponen espacios en los que está permitido tocar, explorar, jugar, preguntar y sentir, las niñas y los

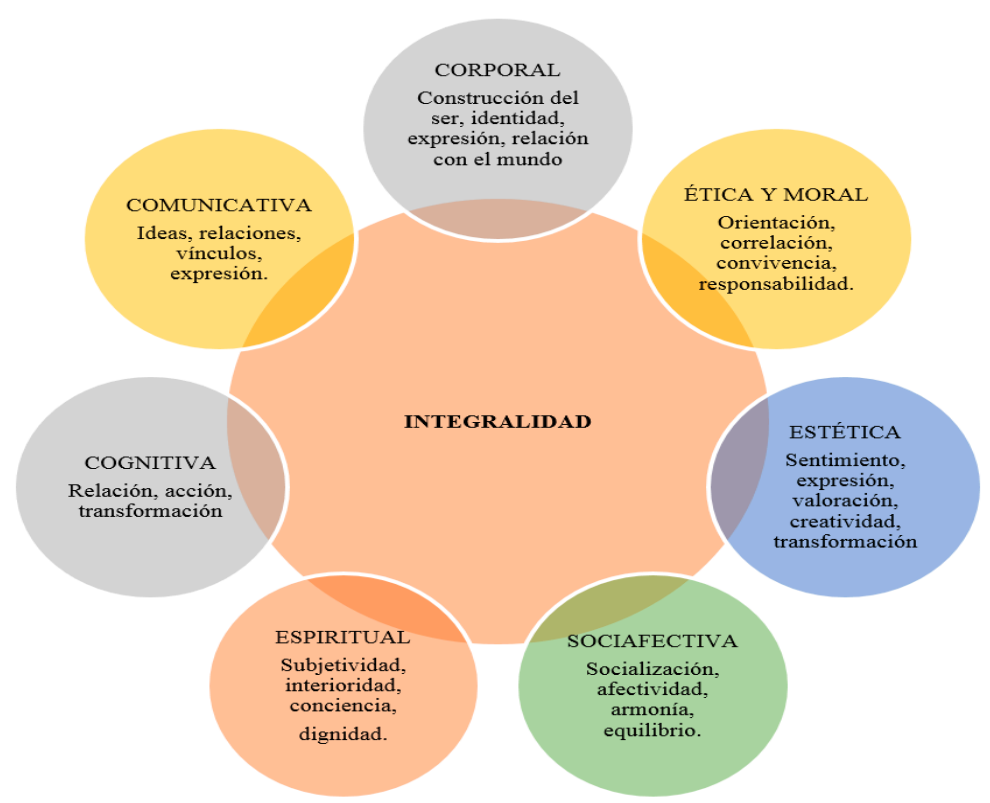

Fuente: Serie lineamientos para preescolar (Ministerio de Educación Nacional) 
niños desarrollan su creatividad como capacidad para recrear, sin limitarlos a la faceta de observadores pasivos. En este sentido, los ambientes en la educación inicial deben organizarse o crearse intencionalmente para que se constituyan en escenarios enriquecidos y significativos (Documento No. 20, 2014, p.72)

Se puede evidenciar entonces, que efectivamente el preescolar difiere mucho de la etapa escolar y cualquier intención de academizarlo va en contra de sus principios y de su sentido mismo, sin el cual éste perdería el significado que tiene en el desarrollo del niño (a) como ser integral.

Ahora, con el fin de abordar los juegos coreográficos, es preciso realizar una revisión respecto al concepto de juego desde diversos autores, como se aprecia en la figura 2.

Figura 2. Conceptualización del juego
Ahora bien, respecto al tipo de juegos en la Primera Infancia se encuentra una gran variedad según la edad, desde el juego sensoriomotor en los más pequeños, pasando por la imitación, la simbolización, el juego de roles y reglado; pero entre varias posibilidades, surge específicamente y de manera innovadora el llamado "juego coreográfico" como posibilitador del desarrollo de habilidades rítmicas, expresivas, comunicativas y sociales; un tipo concreto, especial de juego que integra la música, el movimiento, la actuación y la danza convirtiéndose en dispositivo de empoderamiento del docente para el logro de una educación integral.

Es así, como "El juego coreográfico es una estrategia didáctica que permite desarrollar habilidades rítmicas, expresivas, comunicativas y sociales, que se proyectan en una coreografía a través de expresiones

\begin{tabular}{|c|c|}
\hline roos & $\begin{array}{l}\text { "El juego es objeto de una investigación psicológica especial, siendo el primero en constat } \\
\text { juego como fenómeno de desarrollo del pensamiento y de la actividad". }\end{array}$ \\
\hline tsky & $\begin{array}{l}\text { "El juego surge como necesidad de reproducir el contacto con lo demás. Naturaleza, origt } \\
\text { juego son fenómenos de tipo social, y a través del juego se presentan escenas que van n } \\
\text { instintos y pulsaciones internas individuales" }\end{array}$ \\
\hline laget & $\begin{array}{l}\text { "El juego forma parte de la inteligencia del niño, porque representa la asimilació } \\
\text { reproductiva de la realidad según cada etapa evolutiva del individuo" }\end{array}$ \\
\hline & $\begin{array}{l}\text { "El juego que está controlado por el propio jugador, le proporciona a éste la primera y m } \\
\text { oportunidad de pensar, de hablar e incluso de ser él mismo" }\end{array}$ \\
\hline Huizinga & •"El juego es más viejo que la cultura". \\
\hline ONU & $\begin{array}{l}\text { •"El niño deberá disfrutar plenamente de juegos y recreaciones; la sociedad y las autoridades } \\
\text { esforzarán por promover el goce de este derecho". }\end{array}$ \\
\hline
\end{tabular}

Fuente: elaboración propia. 
corporales... López, \& Valbuena (2015) Dentro de los elementos del juego coreográfico se encuentran la música, la expresión corporal, la expresión verbal y la expresión gráfica. Respecto a estos elementos, autores como (Robinson, 1992) pionera de la danza contemporánea en paralelo con su carrera de bailarina y coreógrafa en su obra "El niño y la danza" reconoce el juego e incluye temas como el cuerpo, los sentimientos, las personas del entorno, la música entre otros, ofreciendo respuestas a las necesidades del niño (a) y a sus interrogantes, motivándole a la investigación personal a través de ambientes propicios de descubrimiento.

Por su parte Laban (2006) en su obra maestra "El dominio del movimiento" considera el movimiento como medio esencial de expresión artística y como posibilidad de construir significados, en concordancia con lo afirmado por Piaget respecto a la construcción del símbolo en el niño.

De otro lado, las fases que se desarrollan en un juego coreográfico son:

- La preparación que consiste en la planeación y construcción del proceso completo a través de la creación de una historia que luego se adaptará para danzar; el mensaje y los personajes que intervienen, vestuario, división de la historia por cuadros escénicos y selección de una melodía acorde a la misma al igual que la elección de la coreografía. Además, la elaboración del cuadro de aprendizajes.
- La implementación: narración de la historia, exploración en las sesiones de clase, realización del montaje y ensamble de los cuadros escénicos gradualmente.

\section{- La presentación del juego coreográfico ante sí mismos o un público familiar o académico, para finalizar.}

En consecuencia, todo lo descrito demuestra que el juego constituye en gran parte el sentido mismo del preescolar porque es una característica del niño (a) en ésta etapa de desarrollo y se debe aprovechar todo el potencial de educar a través de éste, pues conlleva aprendizajes que no son posibles de lograr a través de otras formas: "todos los aprendizajes más importantes de la vida se hacen jugando en la primera etapa de vida (de 0 a 6 años). De aquí la importancia del juego en estas edades y el permitirles explorar en libertad" (Tonucci, 2015).

\section{Desarrollo Metodológico}

En relación con el tipo de investigación que se está desarrollando y debido a que este análisis investigativo se fundamenta en observar y determinar las experiencias, el pensamiento acerca del significado que tiene la educación preescolar y el sentido que los docentes le dan en la práctica. Es preciso citar a Erickson, quien expresa que:

La investigación cualitativa hace mejor y más esencialmente es describir incidentes clave en términos descriptivos funcionalmente relevantes y situarlos en una cierta relación con el más amplio contex- "todos los aprendizajes más importantes de la vida se hacen jugando en la primera etapa de vida (de 0 a 6 años). De aquí la importancia del juego en estas edades y el permitirles explorar en libertad" 
to social, empleando el incidente clave como un ejemplo concreto del funcionamiento de principios abstractos de organización social (Erickson, 1977, p. 61).

Teniendo en cuenta lo anterior el estudio tiene un enfoque socio-crítico, emancipatorio, cuyo propósito es "develar creencias, valores y supuestos que subyacen en la práctica educativa" (Arnal et al., 1994: 36). En esta concepción de investigación se rechaza la neutralidad del investigador, los resultados del proceso llevan a una acción transformadora de la realidad, en este caso la resignificación del sentido de la educación preescolar, con la intervención de los actores y participantes (padres, profesores $\mathrm{y}$ niños/as). Algunos de sus representantes son: Giroux (1997), Freire (2008) y Carr y Kemis (1988).

Mientras que el tipo de investigación estará centrado en la propuesta de Elliott (1994) denominada investigación accion, la cual busca contribuir un cambio de mentalidad en cuanto al sentido de lo que debe ser la educación preescolar. Complementando con Kurt Lewin (1988) quien determina que "la investigación acción permite vincular el estudio de los problemas en un contexto determinado con programas de acción social de manera que se logre simultáneamente conocimientos $\mathrm{y}$ cambios sociales".

En concordancia, se propone el juego coreográfico como una posibilidad para resignificar el sentido de la educación preescolar desde la música y la expresión corporal, verbal y gráfica, con el propósito de desarrollar las habilidades rítmicas, expresivas, comunicativas y sociales que conllevan a potenciar las dimensiones en los niños/as de transición.

Para el desarrollo de la presente investigación que se encuentra en la primera fase, se tienen en cuenta las fases de la investigación acción descritas por Elliott:

- Identificación de una idea general: descripción e interpretación del problema a investigar, en ésta se realiza un acercamiento previo a la institución educativa, con el fin de conocer el significado que la maestra le da a la educación preescolar teniendo en cuenta las características del ambiente, las formas de las relaciones, las formas de trabajo, los ambientes de aprendizaje, las estrategias que utiliza y las actividades que presentan más relevancia.

- Planteamiento del plan de acción o acciones a realizar para cambiar las practicas: una vez realizado el análisis de la información de la primer fase, se propondrán las acciones investigativas a partir del juego coreográfico abordado desde una fase de preparación que corresponde a la planificación de los instrumentos para tener acceso a la información; luego una fase de implementación y de presentación del juego coreográfico, teniendo en cuenta en cada uno de estos la música, la expresión corporal, la expresión verbal y la gráfica que 
corresponde a la ejecución del plan de acción; posteriormente se llevará a cabo la evaluación del plan en mención, para lo cual se realizará el registro y sistematización de los datos, teniendo en cuenta los propósitos de cada una de las habilidades que se desarrollan en preescolar, llevando el seguimiento del desempeño de cada niño a través de diarios de campo y rúbricas.

De las fases anteriormente descritas, se está desarrollando la primera fase, para lo cual se realiza la observación del quehacer docente (autorreflexión y reflexión pedagógica), además de las vivencias en el aula de clase con el grupo de estudiantes seleccionados y se ha trabajado con el diario de campo. A continuación, se representan los primeros hallazgos.

Teniendo en cuenta que la observación en el aula es considerada una técnica muy valiosa en la investigación docente y se puede definir como una actividad que contribuye en la recolección de evidencias, sobre los diferentes aspectos que involucran los procesos de enseñanza y aprendizaje en el contexto en el cual se encuentra inmerso el investigador; por tal razón y teniendo en cuenta que la investigación es de corte cualitativo, el tipo de observación que más se adecua a la obtención de datos e información de manera real donde el investigador se involucra $\mathrm{y}$ vive la experiencia en el ambiente cotidiano de los sujetos, se denomina "La observación participante, como su nombre indica, consiste en observar al mismo tiempo que se participa en las actividades propias del grupo que se está investigando" (Bisquerra, 2014, p 332).

Con relación a la reflexión pedagógica y autorreflexión es necesario destacar los aportes que hace Stephen D. Brookfield citado por Brusadelli y Campaña (2016), en el sentido en el que

Un docente reflexivo es aquel que reconoce que como docente no puede estar ajeno a lo que ocurre en el aula, ya que enseñar es un proceso complejo y de un constante ida y vuelta con el alumno; el docente debe poder reflexionar sobre su práctica ya que el significado y la medida de sus acciones no siempre son entendidas de la misma manera por los alumnos.

A partir de lo anterior, se realiza una primera reflexión que relata los inicios de la investigadora, en su formación como licenciada, seguido de un recuento de la experiencia como docente de educación preescolar y posteriormente de los momentos en los que grupalmente se cuestiona sobre labor con algunos compañeros de la primaria de la misma institución, donde actualmente labora:

El Preescolar es un nivel único de particular "florecimiento" en todos los aspectos. Durante la formación profesional universitaria se logra una visión maravillosa de lo que constituye el preescolar: el trabajo con la familia, el aporte a la sociedad, la atención de los intereses y necesidades de los niños, que cambia un poco (o más bien bastante) cuando en 
la realidad se_incurre en el sector privado para trabajar y se encuentra la competitividad a costa de los niños/ as; en ese ambiente el profesional va "untándose" gradualmente de "plantillas" para realizar tal o cual cosa: esto se hace así, se comienza por este color...se ve primero tal cosa... se enseña a leer así... y lo visto en la universidad se va nublando, opacando hasta casi no percibirse, se va cubriendo como con costritas de una realidad gris disimulada con color hasta formar una concha que va desplazando la literatura, el arte, la exploración del medio, el juego pilar fundamental... el sentido mismo de la educación... quedando sólo una sentencia, y sí, un juego, pero uno sombrío adultocéntrico de competencia insana, una carrera de preprimaria alimentada por los mismos maestros/as y cuyos mayores fanáticos son tristemente los padres y madres de familia.

Se llega a un punto de cuestión: ¿por qué debo actuar así? ¿Qué o quién me presiona? ¿O soy yo misma la que me dejo llevar por ese mar que trata de arrastrarme y al que me debo resistir? ¿Qué es pertinente y qué no en el preescolar? ¡No más!!!!! ¡Quiero cambiar! ¡Quiero descubrir algo mejor...LO MEJOR! Es un grito en el silencio. Un grito que se ha hecho más fuerte cada vez, que me ha llevado a cuestionar y replantear mi práctica pedagógica, una mirada vuelta a los niños/as y a mí misma, un alto en un mundo de locura que apremia, que avanza como gigante al parecer por encima de lo que sea, pisando todo en aras de la educación, sin pensar, sin detenerse, llevándose a su paso los sueños, arrasando con los niños/as sin que importe el daño o ese "vivir y alimentar el error”.

No sé por qué no hago tantas cosas... quisiera hacer más...ser ejemplo... inspiración de más. Me he puesto a la tarea de buscar, de encontrar, de crear, de descubrir por mí misma el preescolar en su mejor sentido para empoderarlo desde ya hace un tiempo, logrando cambios significativos, ya no tanto "de plantilla", cambios que me orientan, que van virando hacia el norte mostrándome el camino. ¿Hacia dónde quiero llevar esta experiencia? ¡muy lejos! porque no voy a conformarme con poco, construiré y lograré resignificar lo que soy, lo que tengo, lo que hago, ellos lo valen, lo valen todo...Por ellos me aventuré a bordo de mi vocación y no me hundiré porque sigue viva! Muy viva después de varios años, diez de los cuales los he pasado aquí en este querido colegio del sector público.

Niños/as y niñas llegan nuevos cada año, con padres que igualmente incursionan en esta tarea de educar, otros muchos ya conocidos que han decidido confiarme sus tesoros: ¡en mis manos se encomiendan tantas vidas que, si no es para acompañarlas a crecer y brillar, entonces...estaría faltando a mí misma, a mi labor y no tendría sentido lo que hago! Por ello y más, el deseo de responder a esta problemática, un problema mío y de todos, de todos los que buscamos a diario algo mejor, un deseo de no quedarme quieta, rendida, expectante como si tuviera las manos atadas. 
Un problema compartido, vislumbrado también por algunas de mis compañeras de trabajo, sobretodo la profesora de primero y segundo con quienes reflexionamos y realizamos un empalme; son profesionales que como yo sienten la necesidad de un cambio que surja de nosotros. El mundo ha cambiado, pero sigue siendo el mismo que impone al niño/a, que lo desconoce y con ideas bien intencionadas tal vez le hace daño.

Por su parte el diario de campo, ha permitido sistematizar la experiencia correspondiente a la socialización del proyecto investigativo de aula "Astronautas y Terrícolas"; además construimos con los niños/as un programa especial (ver figura 3), para compartir con los padres/madres, profesores y estudiantes de otros cursos.

De esta manera inventamos una bienvenida y unos versitos investigativos con rima (ver figura 4), además preparamos dos poesías y adaptamos una ronda sobre la lluvia. Realizamos tarjetas de invitación, preparamos el aula como escenario decorándola con elementos del proyecto: el cielo, planetas, satélites, asteroides, el sol, la luna, las estrellas...y por supuesto ensayamos la coreografía.

En el gran día esperado nos presentamos con mucha altura valiéndonos además de un micrófono diadema que nos

Figura 3. Programa de socialización del proyecto de aula.

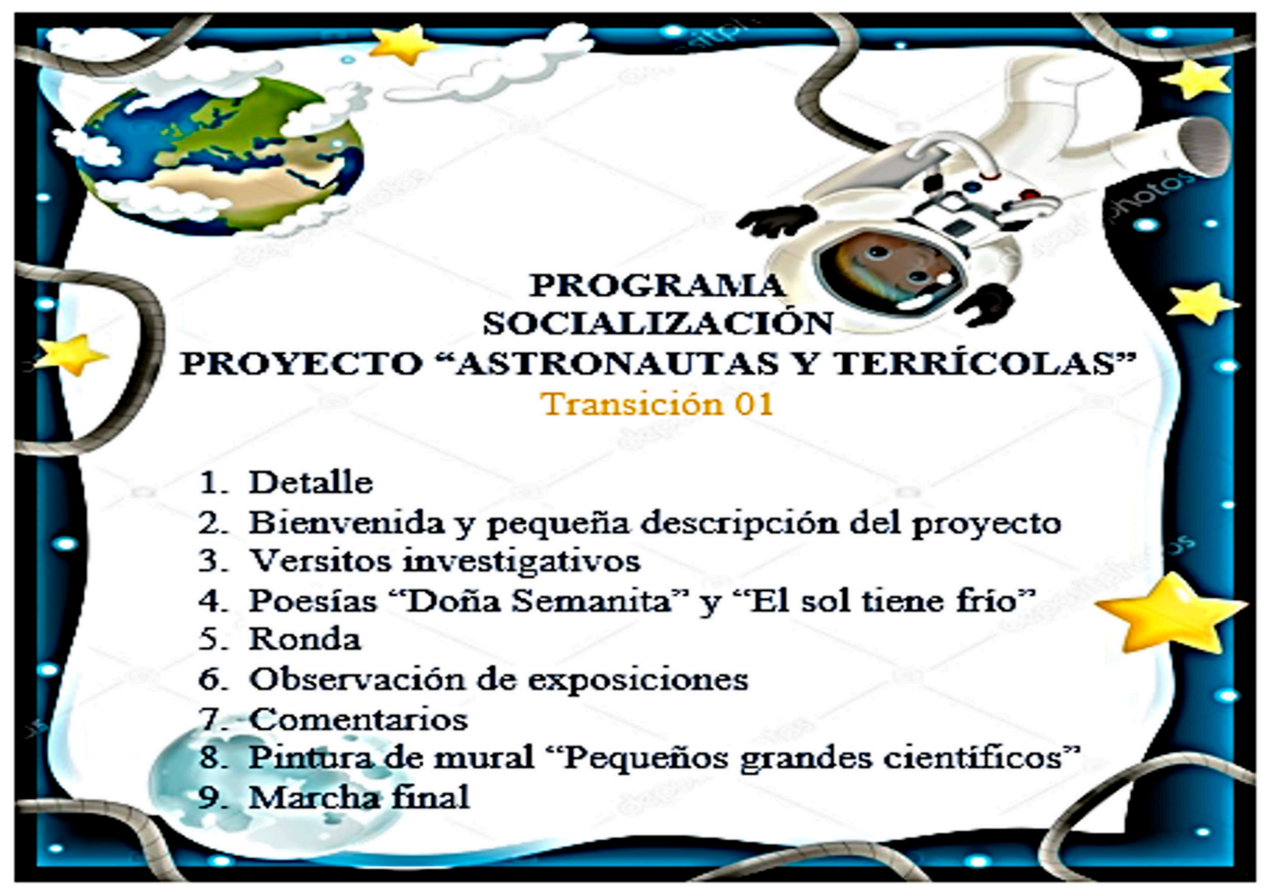

Fuente. Elaboración propia 


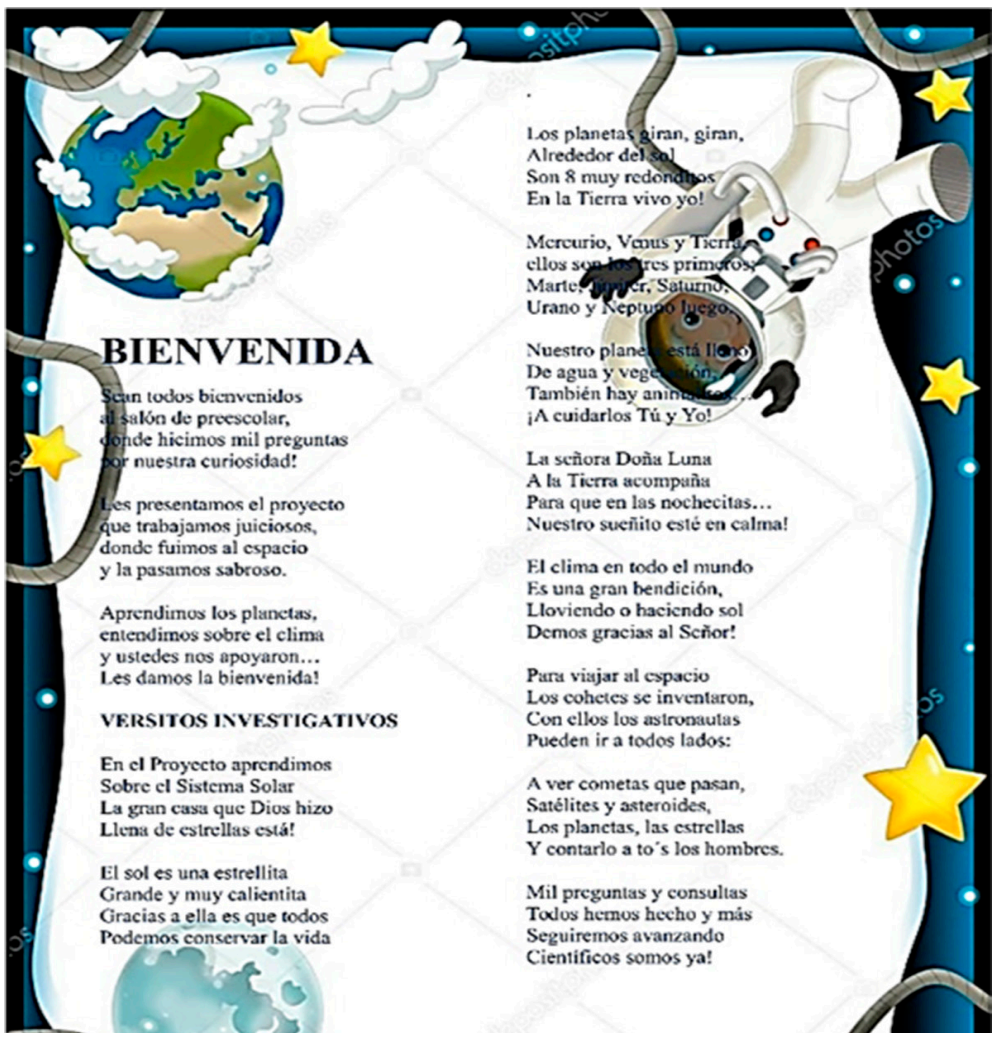

Figura 4. Bienvenida y versitos investigativos.

Fuente. Elaboración propia

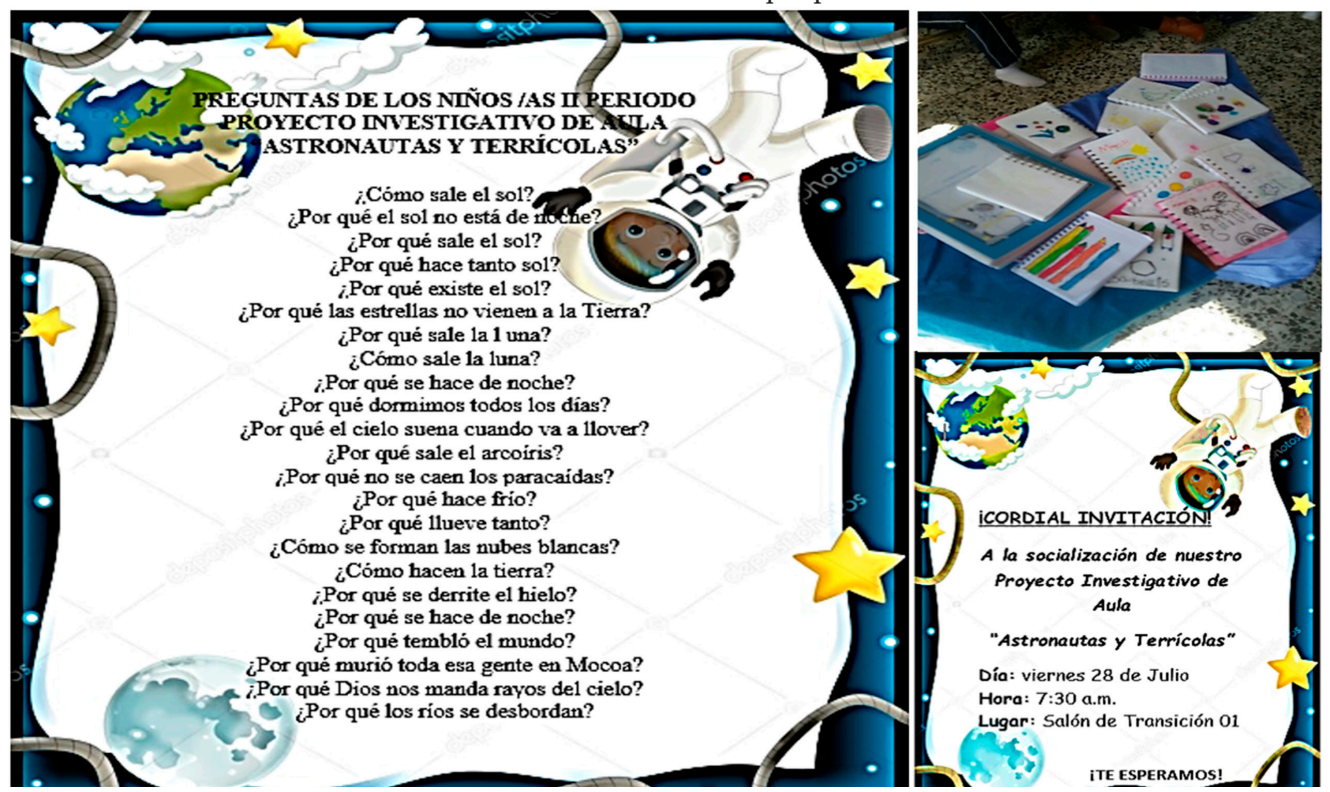

Figura 5. Preguntas, tarjetas y libretas de investigaciones. Fuente. Elaboración propia. 
hizo sentir como verdaderos artistas al ritmo de la guitarra, con el vestuario apropiado: impermeable y botas de lluvia. Al final expusimos nuestra libreta de investigaciones con nuestros dibujos y escritos espontáneos y nuestro álbum de consultas acorde a las preguntas que formulamos (ver figura 5) y decoramos el nuevo muro blanco que pintamos la semana pasada con ayuda de nuestros papitos, con las huellas de nuestras manos en colores vivos, alegres como nosotros titulándolo "Pequeños Grandes Científicos” ¡Eso somos, y seguiremos creciendo paso a paso con el deseo de descubrir el mundo!

\section{Conclusiones}

La Autorreflexión sobre el quehacer pedagógico a la luz de la realidad, se convierte en el primer paso para la transformación y mejoramiento de la práctica en beneficio de los niños (as) en educación preescolar hacia la resignificación.

La práctica pedagógica requiere espacios de formación permanente que permitan respaldar y relacionar el quehacer con el conocimiento y la actualización, depurando concepciones acomodadas y rutinarias.

Muchas de las prácticas preescolares actuales obedecen a las presiones del medio y requieren si no intervención inmediata, reflexión rumbo a la resignificación.

Con claridad en varios apartados se resalta el juego como actividad rectora del preescolar y elemento característico de la naturaleza del niño (a) quien debe participar activamente, por lo cual propiciar este tipo de ambientes contribuye con su pleno desarrollo.

\section{Referencias}

Bisquerra, R. (2014). Metodología de la investigación educativa. Madrid. Editorial la Muralla S.A.

Bruner, J. (1995). Acción, pensamiento y lenguaje. Madrid: Alianza.

Brusadelli, M., \& Campaña, Y. (2016). Autorreflexión y formación del profesorado: la importancia del autorreflexión en los alumnos del profesorado de inglés. Jornadas de Investigadores en Educación.

Carr, W., \& Kemmis, S. (1988). Teoría crítica de la educación. La investigación-acción en la formación del profesorado. Barcelona: Martínez Roca.

Cruz, J. C. (2016). Influencia del Juego Coreográfico en los Procesos de Atención y Memoria de los Niños de Grado Primero Jornada Tarde del Colegio Marsella I.E.D. Recuperado de http://repository.libertadores.edu.co/ bitstream/11371/1070/1/CruzCastilloJannethCarolina.pdf 
Da Silva, T. (1995). El proyecto educacional moderno: identidad terminal. Revista Propuesta Educativa, (13), 5-10.

Elliot, J. (1994). La investigación acción en educación. Madrid: Morata.

Erickson, K. (1976). Everythingin Its Path. Simon and Schuster, Nueva York.

González, X., Solovieva, Y., \& Quintanar, L. (2014). El juego temático de roles sociales: aportes al desarrollo en la edad preescolar. Avances en Psicología Latinoamericana, 32(2).

Groos, K. (1902). Les jeux des animaux. París.: Félix Alcan Éditeur.

Hernández, L., González, María, G., \& Yudy. (2015). Estrategias Didácticas del juego coreográfico que resignifican la enseñanza de la danza en la Básica Primaria de Instituciones educativas de Bogotá. Recuperado de http:// repository.lasalle.edu.co/bitstream/handle/10185/3884/85131207_2015. pdf?sequence $=3$

Huizinga, J. (2000). Homo ludens. Madrid: Alianza/Emercé.

Jaramillo, L. (2011). Concepción de infancia. Zona próxima.

Laban, R. (2006). El dominio del movimiento. Madrid: Fundamentos.

Lewin, L., \& Martha, J. (1988). La teoría de campo en la ciencia social.

Másmela, E., \& Pacheco, S. M. (2014). Políticas públicas y orientaciones pedagógicas como fundamento para la construcción del currículo para la educación musical en preescolar. Recuperado de https://repository.javeriana.edu.co/ bitstream/handle/10554/12361/MasmelaRuizEdwin2014.pdf?sequence=1

Melo, P., \& Hernández, R. (2014). El juego y sus posibilidades en la enseñanza de las Ciencias Naturales. Innovación Educativa, 24.

Ministerio de Educación Nacional. (1994). Ley General de Educación: Ley 115. Bogotá D. C.

Ministerio de Educación Nacional. (1998). Lineamientos Curriculares Preescolar. Bogotá D. C.

Ministerio de Educación Nacional. (2014). Documento No. 20, Serie de orientaciones pedagógicas para la educación inicial en el marco de la atención integral: Sentido de la educación inicial. Bogotá D. C.

Montero, J., Moreno, E., \& Veloza, M. (2015). Rondas, rimasy juegos coreográficos como recursos lúdicos de mejoramiento convivencial. Recuperado de http://repository. libertadores.edu.co/bitstream/11371/181/3/ConstantinoJossaMontero.pdf

Peña, A., \& Castro, A. (2012). Profe: te invito a jugar. El juego un espacio para la participación infantil. Bogotá: Cinde. 
Piaget, J. (1956). Teoría del Juego. Recuperado de https://actividadesludicas2012. wordpress.com/2012/11/12/teorias-de-los-juegos-piaget-vigotsky-kroos/

República de Colombia, Presidencia (1997). Decreto 2247 de septiembre 11 de 1997: por el cual se establecen normas relativas a la prestación del servicio educativo del nivel preescolar y se dictan otras disposiciones. Bogotá D. C.

Robinson,J.(1992). ElNiñoyla Danza. Barcelona:Octaedtro. Recuperado de https:// www.casadellibro.com/libro-el-nino-y-la-danza/9788480630054/222428

Soto, I. (2012). Sociología de la infancia: las niñas y los niños como actores sociales. Revista de sociología, (27).

Tonucci, F. (2015). Los juegos del Taller de Bella. Recuperado de https://eltallerdebella. wordpress.com/2015/01/14/los-aprendizajes-mas-importantes-de-la-vida-sehacen-jugando-los-juegos-del-taller-de-bel-la/

Tovar, J. (2016). El sentido de la relación juego coreográfico - bailes populares en la recreación: una revisión bibliográfica. Recuperado de http://bibliotecadigital. univalle.edu.co/bitstream/10893/9407/1/3464-0510791.pdf

López, C., \& Valbuena, Z. (2015). Historias para danzar juegos coreográficos, una metodología para divertirse y aprender. Revista Internacional Magisterio.

Vigotsky, L. (1924). Teoría del Juego. Recuperado de https://actividadesludicas2012. wordpress.com/2012/11/12/teorias-de-los-juegos-piaget-vigotsky-kroos/ 